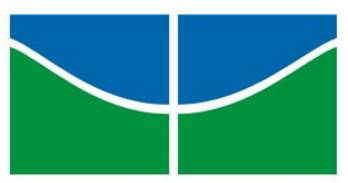

Universidade de Brasília

Centro de Excelência em Turismo

Pós-Graduação Lato Sensu

Curso de Especialização em Hotelaria Hospitalar

A PERCEPÇÃO DO PROFISSIONAL NUTRICIONISTA SOBRE A GASTRONOMIA HOSPITALAR: UM ESTUDO DE CASO SOBRE UM HOSPITAL PARTICULAR DO DISTRITO FEDERAL

Cássia Maria Ferreira Borges

Orientadora: Ms. Verônica Ginani 


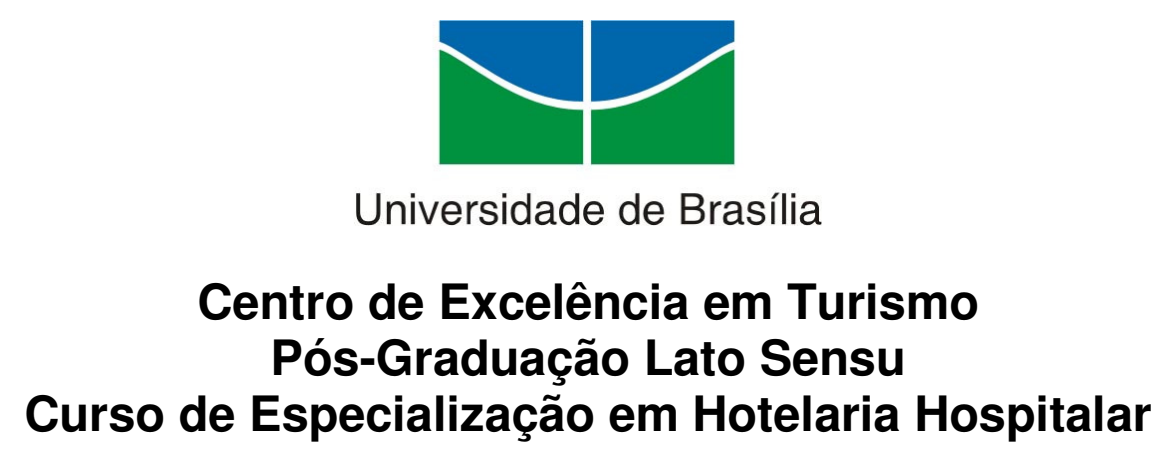

\section{A PERCEPÇÃO DO PROFISSIONAL NUTRICIONISTA SOBRE A GASTRONOMIA HOSPITALAR: UM ESTUDO DE CASO SOBRE UM HOSPITAL PARTICULAR DO DISTRITO FEDERAL}

\section{Cássia Maria Ferreira Borges}

Orientadora: Ms. Verônica Ginani

$$
\begin{aligned}
& \text { Monografia apresentada ao Centro de } \\
& \text { Excelência em Turismo - CET da Universidade } \\
& \text { de Brasília - UnB, como requisito parcial à } \\
& \text { obtenção do grau de Especialista em Hotelaria } \\
& \text { Hospitalar. }
\end{aligned}
$$




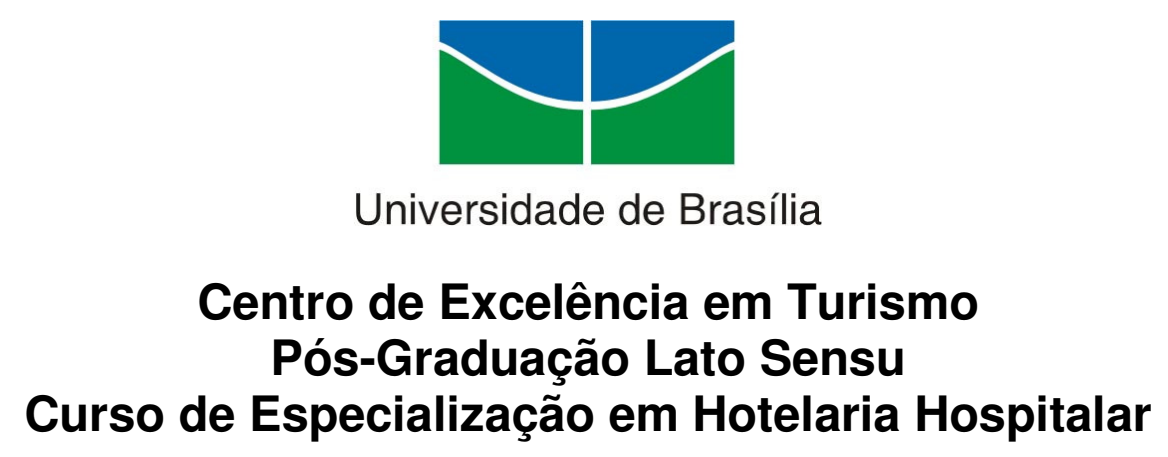

Cássia Maria Ferreira Borges

Aprovado por:

Orientador: MS. Verônica Ginani

Dra. lara Lúcia Gomes Brasileiro

MS. Ana Rosa D. Santos 
Borges, Cássia Maria Ferreira

A Percepção do Profissional Nutricionista sobre a Gastronomia Hospitalar: um estudo de caso sobre um hospital particular do Distrito Federal. Cássia Maria Ferreira Borges Brasília, 2009.

Monografia (especialização) - Universidade de Brasília, Centro de Excelência em Turismo, 2009.

Orientador: Verônica Ginani

1. Hotelaria Hospitalar 2. Gastronomia Hospitalar

3. Nutricionista 4. Alimentação 


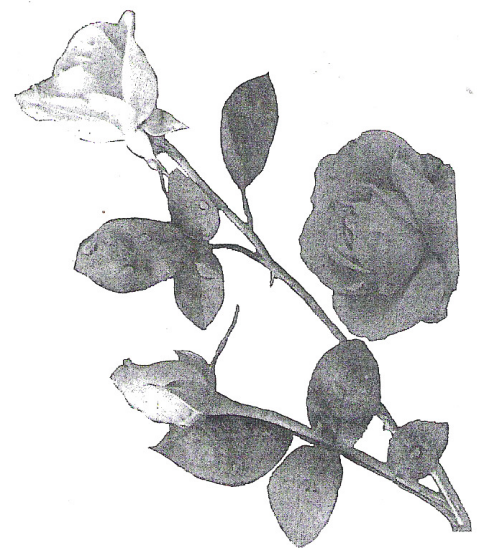

Dedico este trabalho com o mais profundo amor e afeição às minhas filhas, ao meu marido e a todos os profissionais de saúde que optaram pela vocação de trabalhar com a cura! 


\section{AGRADECIMENTOS}

Agradeço, primeiramente, a Deus, aos meus pais, razão de minha existência.

Às minhas grandes amigas do curso e a todos os profissionais que

participaram direta ou indiretamente para a elaboração deste. 
Feliz o homem que come comida, bebe bebida e por isso tem alegria.

Fernando Pessoa 


\section{RESUMO}

Este trabalho tem como objetivo avaliar os critérios mais importantes para a Gastronomia Hospitalar na visão do profissional nutricionista. A revisão bibliográfica abordou a definição de Hotelaria Hospitalar e temas relacionados à Gastronomia Hospitalar, como a alimentação, a nutrição e a dietética; o serviço de alimentação e o papel do profissional nutricionista. A identificação dos critérios, de acordo com a sua importância foi obtida através de aplicação de um questionário com perguntas fechadas direcionadas a nove nutricionistas de um hospital particular do Distrito Federal. Após a análise de todos os questionários foi possível identificar que a aparência dos funcionários, o sabor, os utensílios adequados e o treinamento de funcionários são os critérios mais significativos na opinião das nutricionistas do referido hospital. Vale lembrar que, para a Gastronomia Hospitalar propriamente dita, todos os critérios citados são de suma importância. Portanto, concluiu-se que falta uma visão mais abrangente sobre o tema Gastronomia Hospitalar por parte dos profissionais entrevistados.

Palavras-chave: Alimentação; Gastronomia Hospitalar; Hotelaria Hospitalar; Nutricionista. 


\begin{abstract}
This research has as objective to appraise the most important Gastronomy criterion in the Hospital under the nutritionist view point. The literature review focused the definition of Hospitality and Gastronomy in the hospital, as food, nutrition and diet, the food service and the nutritionist performance. The identification criterion, according to its importance was reach through the closed questions directed to nine nutritionists from a private hospital of Federal District. After analyzing all the questionnaires, it was possible to identify that the professionals' appearance, the taste, the right tool and the training of the professionals are the criterions most important under the nutritionists view point. Its good to remember that: for the really Hospital Gastronomy all of these criterions are very important, so it follows that is necessary a better view point about the Hospital Gastronomy topic by the nutritionists interviewed.
\end{abstract}

Keywords: Food; Hospital Gastronomy; Hospital Hospitality; Nutritionist. 


\section{LISTA DE ILUSTRAÇÕES}

Figura 1: Áreas de Conhecimento da Hotelaria Hospitalar

Figura 2: Resultados da percepção do profissional nutricionista quanto ao nível de importância dos principais critérios da Gastronomia Hospitalar.

Figura 3: Gráfico consolidado dos critérios avaliados da Gastronomia Hospitalar na visão dos nutricionistas do referido hospital. 


\section{LISTA DE ABREVIATURAS}

G.H - Gastronomia Hospitalar

H.H - Hotelaria Hospitalar

OMS - Organização Mundial de Saúde

S.A - Serviço de Alimentação

UND - Unidade de Nutrição e Dietética

TD - Técnica e Dietética 


\section{SUMÁRIO}

1 INTRODUÇÃO

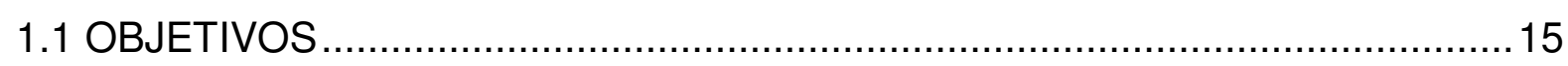

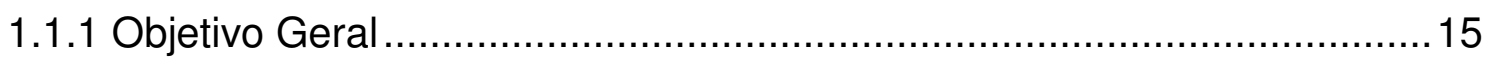

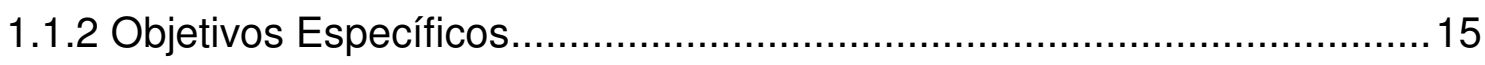

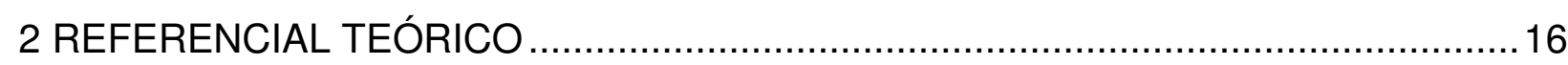

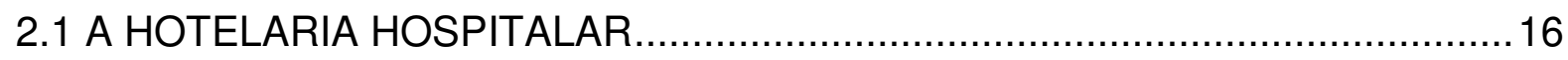

2.1.1 Qualidade e Hospitalidade ............................................................... 18

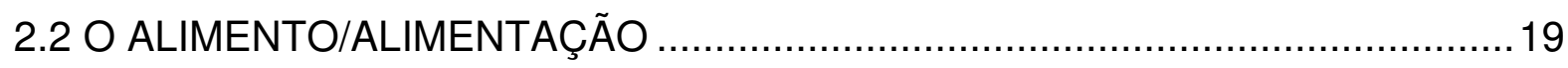

2.2.1 A Arte Culinária e a Técnica Dietética ................................................21

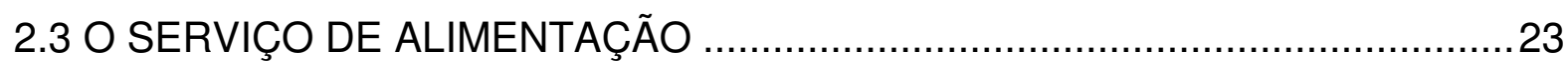

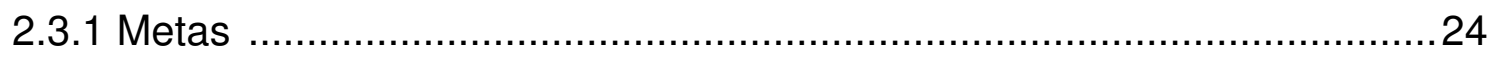

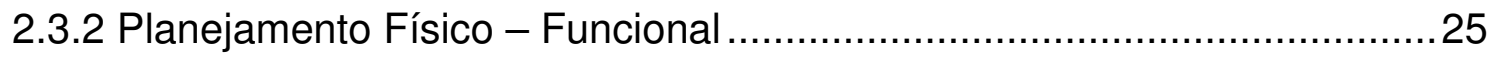

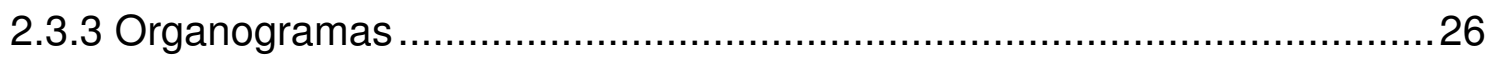

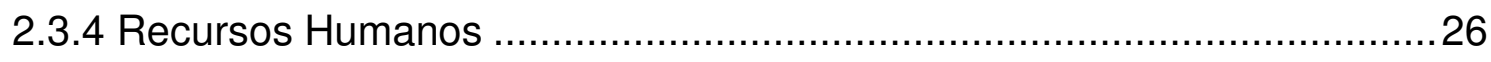

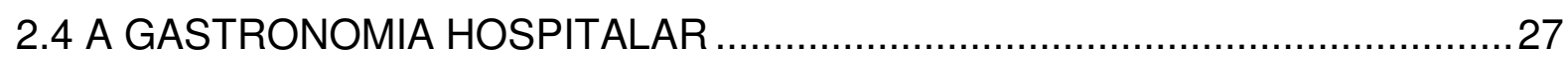

2.4.1 Implementação e Implantação da Gastronomia Hospitalar .....................29

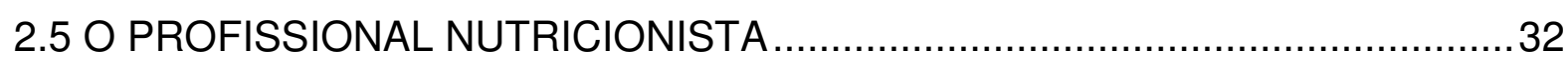

2.5.1 Atribuições do nutricionista ..............................................................

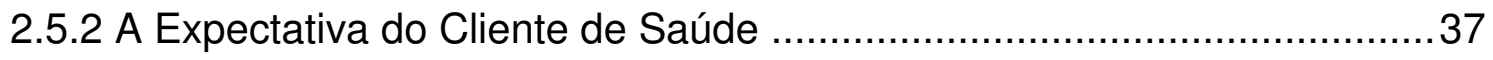

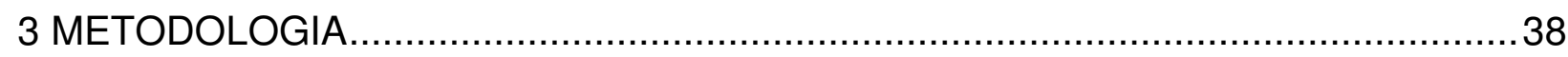

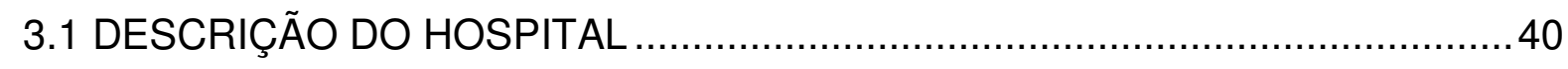

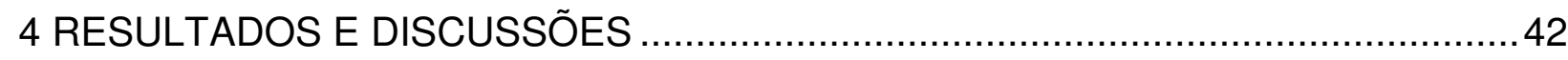

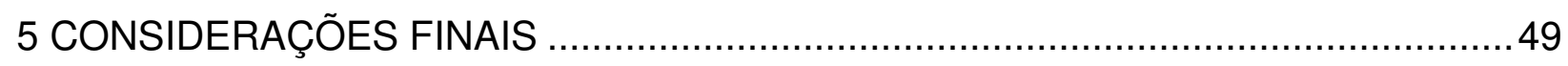

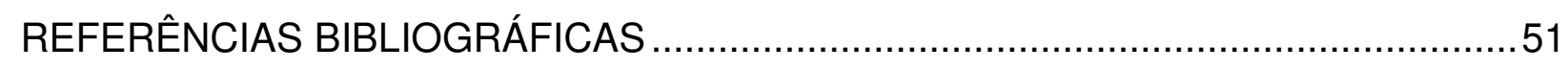

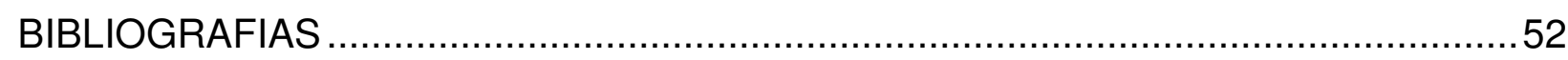

ANEXO: REGULAMENTAÇÃO DA PROFISSÃO DE NUTRICIONISTA ......................53

APÊNDICE: FICHA DE COLETA DE DADOS PARA AVALIAÇÃO ….........................55 


\section{INTRODUÇÃO}

Desde a antiguidade, a associação entre a alimentação, a dietética e a saúde é descrita como recurso terapêutico. No entanto, apenas a partir do século XX, a Ciência da Nutrição apresenta-se consolidada e evolui ao lado dos avanços da área hospitalar. Souza apud Jorge, 2006 ressalta que, durante as duas últimas décadas, houve um avanço considerável com relação aos conhecimentos na área da Nutrição e Dietética. A importância do fato se destaca na observação do quadro de pacientes internados em Unidades Hospitalares. A desnutrição hospitalar, no início do novo milênio, é provavelmente uma das doenças de maior prevalência e incidência nos hospitais, chegando a atingir de $30 \%$ a $50 \%$ dos internados. Nota-se, então a importância da terapia nutricional para o pronto restabelecimento dos pacientes (MAGNONI, 2005).

No Brasil, os hospitais vêm sentindo a necessidade de expandir seus serviços, principalmente, no setor da Gastronomia Hospitalar. O objetivo é melhorar a qualidade de vida dos pacientes, que por sua vez, devem se sentir cada vez menos pacientes e mais clientes.

A nutrição adequada e orientada associa sinergismos ao tratamento médico, seja na orientação dietética básica e clássica, na educação preventiva às doenças ou mesmo na prevenção de distúrbios graves (MAGNONI, 2005),

De acordo com Duarte (2006), atualmente os hospitais que procuram qualidade em alimentação e atendimento ao cliente, aliam a Dietoterapia à Gastronomia. Essa combinação, acrescida da satisfação da clientela, hoje é chamada de Gastronomia Hospitalar (G.H.). 
Os clientes hospitalares procuram a unidade de saúde para atenuar a dor ou tratar doenças. Nesse universo de atendimento médico e atenção à saúde, o cardápio deve incorporar momentos de "alegria". A relação positiva entre o momento da alimentação e a realidade individual do mundo extra-hospitalar pode promover ações sinérgicas ao tratamento medicamentoso (MAGNONI, 2005).

Nesse contexto, percebe-se que a apresentação das dietas mudou muito nos últimos anos, tanto nos hospitais públicos como nos particulares. Há alguns anos a preocupação dos nutricionistas era oferecer uma Dieta "Balanceada/Equilibrada", onde o foco eram os cálculos dessas dietas, sem a preocupação com o modo que eram oferecidas ou apresentadas ao cliente.

Atualmente, com a chegada da Gastronomia Hospitalar esse cenário está mudando. Além de se preocupar com a quantidade e qualidade nutricional das dietas, há a preocupação com os processos de cocção (para preservar nutrientes; manter a coloração e outras); com o sabor (utilizando ervas/condimentos em dietas restritas) e aparência (utilização de louças brancas, detalhes no posicionamento dos pratos/ decoração, utilizando cortes especiais de legumes, folhas.) e o impacto que todos esses fatores provocam no cliente e em sua saúde.

Sendo assim, a Gastronomia Hospitalar é um tema que fascina. É um grande diferencial para a qualidade dos serviços prestados pelos hospitais, visto que está diretamente ligada ao "prazer" e a recuperação do cliente de saúde.

O presente trabalho tem como tema a Dietoterapia e a Gastronomia Hospitalar. Visa avaliar a percepção do profissional nutricionista em relação aos critérios mais importantes para a implantação da Gastronomia Hospitalar; quais as 
dificuldades para a implantação desta e acima de tudo, qual o papel do nutricionista neste cenário.

\subsection{OBJETIVOS}

\subsubsection{Objetivo Geral}

Avaliar a percepção do profissional nutricionista sobre os critérios mais importantes da Gastronomia Hospitalar em um hospital particular.

\subsubsection{Objetivos Específicos}

Definir a Hotelaria Hospitalar como importante ferramenta para divulgar o serviço junto à concorrência.

Abordar sobre Alimentação, Dietoterapia e Gastronomia Hospitalar.

Descrever o papel do nutricionista para a implantação da Gastronomia Hospitalar.

> Identificar os critérios mais relevantes da Gastronomia Hospitalar para o profissional nutricionista. 


\section{REFERENCIAL TEÓRICO}

\subsection{HOTELARIA HOSPITALAR}

Jorge (2006) relata que o surgimento e a evolução dos hospitais apresentam avanços clínicos aliados às ações de hospitalidade e hotelaria para a promoção da qualidade de vida dos clientes.

De acordo com Guimarães (2007), a Hotelaria Hospitalar (H.H.) busca aproximar-se da real necessidade do cliente de saúde, preocupando-se em medir suas expectativas e não somente as suas necessidades.

Os conceitos que formam a Hotelaria Hospitalar são importados de três grandes áreas. A interseção de alguns conhecimentos da área de Administração Hospitalar, áreas de saúde e da Administração Hoteleira forma esta "nova" área, conhecida com Hotelaria Hospitalar (Figura 1).

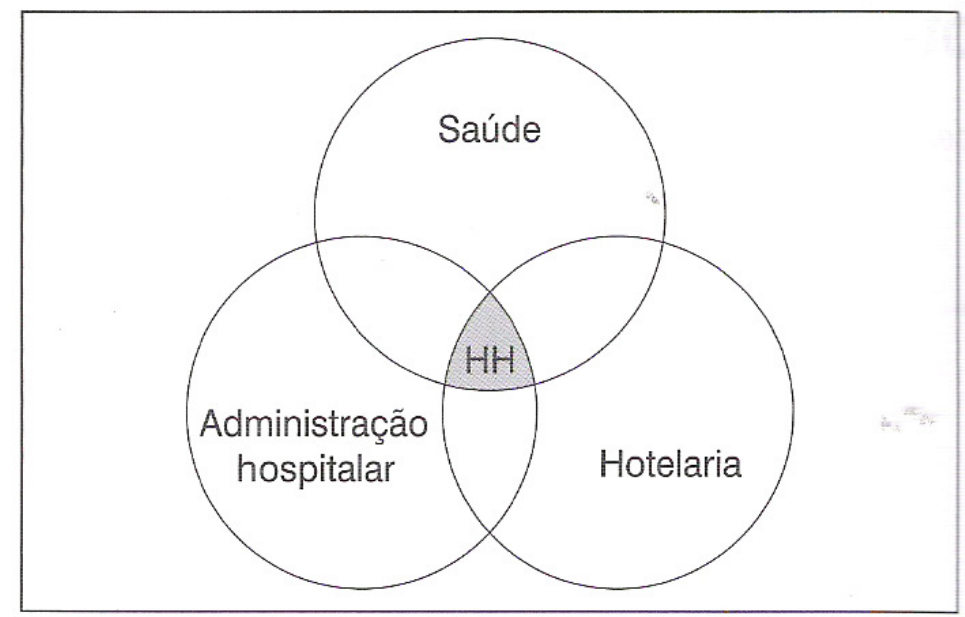

Figura 1: Áreas de Conhecimento da Hotelaria Hospitalar Fonte: Guimarães, 2007 
Guimarães (2007) cita que a Hotelaria Hospitalar é a reunião de todos os serviços de apoio que, associados aos serviços específicos, oferecem o bem estar durante o seu período de internação.

Pode-se dividir a Hotelaria Hospitalar em cinco componentes distintos. Peniche apud Guimarães, 2007 define como "Cinco Hs":

Hospitalar: referente à gestão da hotelaria que tem interação com a equipe assistencial. Por exemplo, a área do Setor de Nutrição e Dietética, ligado a dietoterapia, dietas enterais, parenterais entre outros.

Hoteleiro: refere-se à possibilidade de inserir glamour aos serviços prestados, às técnicas de administração dos serviços de apoio, como técnicas de atendimento telefônico ou balcão, chefe de cozinha e outras, no atendimento ao cliente.

Humanização: talvez seja dos 5 Hs o esforço em "bem atender" mais conhecido nos hospitais. Envolve todos os setores em todos os aspectos de atendimento, inclusive o assistencial, o atendimento ao cliente por médicos, enfermeiras, auxiliares e paramédicos. Leva em conta que o cliente é um indivíduo com necessidades, desejos e aversões, respeitando esses aspectos.

Hospitalidade: uma das várias definições é a do cuidado pelo anfitrião ao hóspede durante sua hospedagem. Em uma instituição de saúde, pode-se entender o desejo espontâneo da mão de obra contratada em receber pessoas na instituição. 
Humor: Pode ser entendido como as possibilidades de entretenimento durante a internação, como: a brinquedoteca, os doutores da alegria, peças de teatro e eventos em geral.

Ainda vale lembrar que o conceito de $\mathrm{HH}$ sugere que se deve reconhecer cada um dos clientes como indivíduos diferentes, com necessidades distintas a serem atendidos e estimulados de forma a fidelizá-los ao serviço prestado.

\subsubsection{Qualidade e Hospitalidade}

Davies (2001) cita que se deve oferecer produtos e serviços de qualidade aos clientes. Mas o que é qualidade?

$\mathrm{Na}$ indústria hoteleira e sob o enfoque de trabalho, define-se qualidade como a prestação contínua de serviços e apresentação de produtos com base nos padrões dos estabelecimentos individuais ou cadeia. Qualidade envolve adaptar, comunicar e manter padrões adequados de desempenho em todas as atividades oferecidas pelo estabelecimento para satisfazer as necessidades dos clientes (DAVIES, 2001).

A qualidade de serviço é o resultado de um esforço de operação para descobrir exatamente o que o cliente quer. Uma vez que essas necessidades e desejos sejam conhecidos, os procedimentos são implementados para atender a essas solicitações de forma efetiva e constante. Há muita verdade no velho ditado: "A cortesia não custa nada, mas vale tudo". Se os funcionários interagem bem com os clientes, acabam influenciando-os para que retornem.

Davies, 2001, p. 27, ainda questiona: o que é um serviço de qualidade em Alimentos e Bebidas? Destaca as possíveis respostas: 
$>$ Um rosto sorridente;

$>$ Excelência em tudo o que se faz;

> Saudar cada cliente com educação;

$>$ Visualizar cada cliente como um VIP ${ }^{1}$;

$>$ Convidar o cliente a regressar quando necessário;

$>$ Criar um bom ambiente;

- Olhar atentamente para o cliente, demonstrando, assim o interesse por ele.

Davies (2001) ainda cita que se deve olhar mais de perto a indústria da hospitalidade e alguns termos associados a ela. Hospitalidade define-se como a recepção e acolhida aos hóspedes, visitantes ou estranhos, com liberalidade e boa vontade. Tal recepção inclui, sempre, proporcionar um ambiente agradável.

\subsection{O ALIMENTO E A ALIMENTAÇÃO}

De acordo com Machado e Teixeira (apud Montanari,1998), durante a Antiguidade muito se escreveu sobre a alimentação e sua relação com a saúde. Os alimentos e as bebidas têm a função de conservar ou dar saúde. No entanto, é preciso descobrir suas especificidades. Somente um bom conhecimento sobre as propriedades dos alimentos permitirá evitar os excessos ou suprir as carências responsáveis pelo desequilíbrio e a doença no corpo humano.

\footnotetext{
${ }^{1}$ VIP: Pessoa muito importante, do inglês Very important person.
} 
Os médicos da Antiguidade justificavam seu interesse pela alimentação na relevância tanto para homens com boa saúde, como para os doentes. Eles explicavam também que uma alimentação apropriada permite obter uma cura mais completa do que a medicina.

Hipócrates (séc. V - IV a.C (apud Montanari,1998), afirmava "que seu alimento seja o seu remédio e que seu remédio seja o seu alimento" (De diaete, de diaeta in acutis, De salubri diaeta).

Galeno (apud Montanari,1998) relata que não temos necessidade o tempo todo de outras ajudas, mas sem a alimentação nem os homens saudáveis, nem os doentes, podem viver.

Analisando afirmações tão antigas e sábias procurou-se uma definição através de uma visão sociológica. De acordo com Poulain (2004), em latim alere significa "nutrir"; o alimento é, portanto, o que nutre o que traz ao homem os elementos que o dispêndio da vida lhe faz perder, tornando indispensável para a sobrevivência.

Tudo que é capaz de reparar a perda das partes sólidas ou líquidas de nosso corpo merece o nome de alimento diz um dicionário do século XVIII (LEMERY, 1702, apud Poulain).

Mas, para que um alimento seja reconhecido como tal, ou seja, capaz de manter a vida, ele não deve somente possuir qualidades nutricionais (conter proteínas, lipídeos, carboidratos e oligoelementos). É preciso que ele seja conhecido e/ ou aceito como tal pelo comedor e pelo grupo social ao qual pertence. 
Para Casotti (2002), todos têm fome, e comer é um grande prazer. Existem três necessidades básicas do homem: alimento, segurança e afeto. Todas caminham juntas, estão entrelaçadas. O alimento é vida. Inúmeros aspectos da vida podem ser compreendidos a partir do conhecimento de seu consumo. Enquanto exercem sua capacidade de nutrir ou saciar a fome, alimentos também produzem significados.

Santos (2008) relata que no que tange ao ato de comer, tem-se uma prática repleta de gestos, posturas e modos de expressão com uma infinidade de detalhes complexos. Nas práticas alimentares contemporâneas novos gestos e metáforas são também produzidos constantemente relendo as anteriores e criando as novas. Notase hoje, que conversar sobre o corpo e práticas cotidianas é como se fosse abrir a "Caixa de Pandora", que levantam as insatisfações secretas, as pequenas histórias cotidianas, segredos, banalidades, contradições e conflitos que marcam as existências dos seres humanos na vida cotidiana. Desta maneira as questões que conduzem as práticas corporais e alimentares dos sujeitos são ainda mais profundas.

\subsubsection{A Arte Culinária e a Técnica Dietética}

Contemplando a importância da alimentação, Leal (1998) afirma que a arte culinária desperta paixões. A principal preocupação da arte de cozinhar é proporcionar o máximo de prazer a quem come não apenas para saciar a fome, mas principalmente, para ter prazer.

Embora a palavra gastronomia signifique o estudo das leis do estômago, ela tem, hoje, um sentido bem mais amplo. Refere-se à arte de preparar iguarias, 
tornando-as mais digestivas, de modo a obter o maior prazer possível. É tudo que se refere ao homem na medida em que se alimenta.

Leal (1998) afirma que como os pintores fazem com as cores, o verdadeiro cozinheiro tem que tornar as misturas tão homogêneas que de seus próprios sabores resulte apenas um gosto sutil e instigante. Uma harmonia de todos os gostos reunidos, como uma obra de arte.

A Técnica Dietética, de acordo com Philippi (2003), estuda e aplica os princípios e processos básicos da Ciência da Nutrição no organismo humano. Permite o planejamento, a execução e a avaliação de dietas adequadas às características biológicas, socioeconômicas, culturais e psicológicas dos indivíduos.

A Técnica Dietética é a sistematização e o estudo dos procedimentos para tornar possível a utilização dos alimentos visando a preservação do valor nutritivo e a obtenção dos caracteres sensoriais desejados.

De acordo com Leal,1998 os objetivos da Técnica e Dietética (TD) podem ser classificados em:

a) Dietético: consiste em adequar a forma de preparo dos alimentos da dieta às necessidades fisiopatológicas do sujeito.

b) Digestivo: consiste em modificar os alimentos por meio de processos culinários a fim de facilitar a digestão.

c) Nutritivo: consiste em selecionar os melhores métodos de preparo de alimentos para otimização e conservação máxima do seu valor nutritivo. 
d) Higiênico: consiste em prevenir a ação de fatores externos que possam prejudicar a qualidade dos alimentos, aumentando, assim, sua vida útil.

e) Sensorial: consiste em apresentar o alimento de forma que desperte todos os sentidos, não apenas o paladar, pois cada alimento possui suas próprias características sensoriais (aparência, cor, odor, sabor, consistência e textura).

f) Operacional: consiste em preparar e organizar espaços físicos, materiais, equipamentos e utensílios, planejar os cardápios e capacitar o pessoal relacionado para o trabalho.

g) Econômico: consiste em escolher as técnicas a serem empregadas no preparo de alimentos, considerando os custos e os recursos humanos, materiais e financeiros disponíveis.

\subsection{O SERVIÇO DE ALIMENTAÇÃO}

Segundo o Ministério da Saúde "Em todo hospital deverá ser prestado o Serviço de Alimentação (S.A), unidade de apoio destinada a fornecer as refeições a pacientes e funcionários" (MEZOMO, 2002).

Para Mezomo (2002), o S.A é o serviço hospitalar que presta assistência aos pacientes, funcionários e acompanhantes com a distribuição de refeições e a educação alimentar. Proporciona aos comensais uma assistência adequada e educação alimentar, embasadas em fundamentos técnico-administrativos e 
científicos. Possui metas específicas dentro de um planejamento físico-funcional descritos a seguir.

\subsubsection{Metas do Serviço de Alimentação}

Principais metas:

preparar e distribuir, cientificamente, a alimentação destinada aos pacientes, funcionários, acompanhantes e visitantes do hospital, obedecendo as dietas e cardápios preestabelecidos pelo próprio serviço;

prever e prover o serviço de todos os gêneros alimentícios e equipamentos necessários ao desenvolvimento de suas atividades;

receber, conferir, armazenar, registrar, controlar e distribuir os gêneros alimentícios e demais materiais de serviço;

$>$ elaborar e atualizar o manual de dietas de acordo com o parecer do corpo clínico do hospital;

elaborar programas de educação alimentar, para os pacientes internados e de ambulatório e para os funcionários, mostrando-Ihes a necessidade de uma alimentação equilibrada;

elaborar programas de treinamento, para o pessoal do S.A e para o pessoal indiretamente ligado a ele;

programar o estágio (externo) para todo o pessoal do S.A, para atualização profissional; 
> fomentar a pesquisa no campo da nutrição;

$>$ colaborar com as instituições educacionais na formação de profissionais de nutrição, na área de saúde;

colaborar com programas de educação sanitária, desenvolvidos pelo hospital, a serviço da comunidade.

\subsubsection{Planejamento Físico - Funcional do Serviço de Alimentação}

O planejamento físico-funcional do S.A tem como objetivo garantir instalações adequadas e funcionais, assegurando a operacionalização dentro das mais rígidas normas técnicas de higiene (MEZOMO, 2002).

O planejamento físico-funcional envolve uma abordagem adequada dos seguintes aspectos:

$>$ localização do S.A;

$>$ configuração geométrica da cozinha;

> determinação do sistema de distribuição de refeição para pacientes, acompanhantes e funcionários (centralizado, descentralizado, misto);

número de comensais;

logística do abastecimento;

tipo de combustível a ser utilizado;

determinação e dimensionamento das áreas trabalhos;

dimensionamento, adequação e distribuição dos equipamentos de acordo com o fluxo estabelecido;

planejamento dos sistemas hidráulicos e elétricos e instalações anexas; 
revestimentos.

\subsubsection{Organograma}

O gráfico organizacional deve apresentar a estrutura da organização de forma objetiva:

$>$ a estrutura hierárquica, definindo os diversos níveis;

$>$ os órgãos componentes da estrutura organizacional;

os canais de comunicação entre os setores ou órgãos.

\subsubsection{Recursos Humanos}

O homem é o elemento-chave de qualquer organização, e, por se tratar de um ser humano, são imprescindíveis suas reações isoladas e sua interação com o grupo.

Em uma organização hospitalar, o homem representa um patrimônio inestimável e extremamente complexo.

Fatores que devem ser observados na seleção da equipe do S.A:

> hostilidade do ambiente de trabalho;

$>$ conotação social do setor "cozinha";

> responsabilidade das operações processadas na área;

> nível sócio-econômico -educacional de seus participantes; 
$>$ condições físicas e de saúde da equipe.

Uma análise criteriosa dos itens acima citados possibilitará uma seleção qualitativa positiva.

Conclui-se, portanto, que o S.A é uma das unidades administrativas, integrantes da organização hospitalar. Sua estruturação deve estar vinculada a um instrumento formal, favorecendo o estabelecimento desde uma metodologia de trabalho, através da definição dos seus objetivos, das linhas de subordinação e das normas técnicas.

\subsection{A GASTRONOMIA HOSPITALAR}

Para Jorge e Maculevicius (apud GUIMARÃES, 2007), a hotelaria e a arte de bem receber estão intimamente ligadas à alimentação. Pensar no indivíduo enfermo, acamado ou com necessidades especiais, confinado em ambiente fora do lar, leva à percepção que é muito importante trabalhar a alimentação deste indivíduo com cuidado, elaborando-a não só no sentido de suprir suas necessidades básicas de manutenção ou de recuperação da saúde, mas propiciando conforto e bem estar físico e mental. Visando esses aspectos é fundamental a contribuição da Gastronomia Hospitalar (G.H).

A abrangência de conhecimentos relacionada à nutrição e à gastronomia está vinculada a fatores culturais, psicológicos, ambientais, fisiológicos e sensoriais, que inter-relacionados são determinantes da aceitabilidade dos alimentos. Também é condicionada a fatores fisiológicos, assim como estado de saúde, idade, sexo, peso, 
altura e atividade física, que irão determinar variações de necessidades calóricas e de nutrientes.

No meio hospitalar há uma associação de fatores traduzida pelo binômio nutrição x comportamento, visto que os sujeitos são deslocados do seu convívio social. A mudança de ambiente e a alteração do significado simbólico dos alimentos passam a ser limitantes do desenvolvimento normal do apetite. Além disso, há um desequilíbrio do estado de saúde, pela instalação de um processo patológico, que exige atenção especializada no plano de assistência nutricional e dietoterápica.

Atualmente, a visão da dieta hospitalar está sendo ampliada e adaptada às tendências da gastronomia. A busca de aliar a prescrição dietética e as restrições alimentares de clientes a refeições atrativas e saborosas é o desafio para integrar as Unidades de Nutrição e Dietética (UND) a um sistema de hotelaria aprimorado.

A nutrição hospitalar evoluiu apresentando-se como a unidade que tem como objetivo produzir bens e prestar serviços de assistência nutricional. Investe em planejamento e hotelaria, sistematizando seus processos. Estes por sua vez, envolvem a produção, a assistência, o controle financeiro e o gerenciamento de recursos, acompanhando a evolução técnica e tecnológica, a evolução do mercado e da G.H, baseando seu trabalho em projetos e protocolos técnicos e administrativos.

O cliente, antes passivo, agora assume olhares diferenciados sobre seu tratamento, com mais acesso às informações e expectativas crescentes. Como consumidor, torna-se crítico e agente de mudança de seu tratamento. 
A gastronomia aliada à nutrição passa a ser um diferencial no atendimento de expectativas crescentes dos clientes. Exige aprimoramento técnico, assistência nutricional individualizada e estratégias para vencer desafios constantes.

\subsubsection{Implementação e Implantação da Gastronomia Hospitalar}

De acordo com Jorge e Maculevicius (apud GUIMARÃES, 2007), são identificadas algumas propostas para a implementação ${ }^{2}$ da Gastronomia Hospitalar em uma unidade de Nutrição e Dietética:

> Identificação de necessidades e expectativas dos clientes externos, relativas à alimentação e à prestação de serviços de H.H.

Levantamento de necessidades e expectativas junto aos clientes internos (reuniões, entrevistas, diagnóstico situacional), referentes à Gastronomia.

Dstabelecimento de um sistema de H.H e de Qualidade, alinhado à estratégia institucional e às necessidades e expectativas anteriormente definidas.

Avaliação de desempenho através de estabelecimento de metas e análise da evolução de indicadores correlacionada com a assistência a clientes.

Estas etapas permitem a identificação dos elementos fundamentais envolvidos com a G.H, conforme a realidade da Unidade de Nutrição e Dietética.

Os principais elementos a serem identificados são: satisfação do cliente, adequação dietética e aroma; sabor e tempero das preparações; apresentação do

\footnotetext{
${ }^{2}$ Implementação: Ato de implementar/ programar. Levar à prática por meio de providências concretas.
} 
prato e bandeja e atenção do nutricionista às individualidades do cliente; variedade do cardápio, tanto do prato variedade das preparações; treinamento especializado de funcionários, cordialidade no atendimento e rapidez do serviço, número de opções do cardápio, eficiência, agrados ao cliente em datas comemorativas e cardápio especial, bebida que acompanha as refeições, economia de recursos, necessidade da existência de chef de cozinha.

Conforme Jorge e Maculevicius (apud Guimarães,2007), após a identificação dos elementos, recomenda-se a ordenação dos níveis de prioridade de ação:

Prioridade I - ação imediata, com foco no cliente.

Prioridade II - ações de médio prazo, que envolvem a melhoria de prestação de serviços pelas UND

Prioridade III - elementos mais específicos e que podem ocasionar diferenciação de atendimento.

A partir da identificação de prioridade da G.H é possível direcionar as atividades, na medida em que envolve os profissionais na tomada de decisões e plano de trabalho.

Para a implantação ${ }^{3}$ da Gastronomia Hospitalar Jorge e Maculevicius (apud GUIMARÃES, 2007) cita que na prática, a metodologia de produção de refeições e o sistema de qualidade que sigam algumas premissas básicas, favorecem a implantação e a inovação da gastronomia aplicada a dietas hospitalares como:

\footnotetext{
${ }^{3}$ Implantação: Ato de implantar/arraigar/estabelecer-se.
} 
> planejamento de cardápio, mediante pesquisa prévia de cardápios nutritivos, práticos e bem aceitos;

padrão de dietas que permitam flexibilidade de atendimento e possibilite treinamento eficaz da equipe em todos os níveis funcionais;

flexibilidade de atendimento com opções de alimentos e preparações, pesquisa e desenvolvimento de fornecedores;

preparações diferenciadas em cortes, modo de preparo e apresentação, com identificação e implementação de enfeites comestíveis em linha de montagem;

$>$ divisão racional da equipe de preparo de alimentos por lote de alimentos e por preparações, evitando-se fluxo cruzado e permitindo focalização no preparo;

treinamento em linha de montagem centralizada, com utilização de utensílios funcionais;

desenvolvimento de talentos e habilidades manuais entre os colaboradores;

> investimento em cardápio de eventos especiais, com mensagens em bandejas de refeições.

Os desafios e os investimentos constantes são:

treinamento e desenvolvimento de colaboradores, estimulando a formação de especialistas em gastronomia e dietética;

estudo de perspectivas de mercado e desenvolvimento de fornecedores, com foco principal em produtos atrativos para dietas restritas; 
$>$ modernização do sistema de hotelaria, alinhado à estratégia institucional de foco no cliente;

$>$ desenvolvimento de estudos integrados de hospitalidade;

> flexibilidade na linha de atendimento ao cliente;

sistema de opções de cardápios para dietas restritas.

\subsection{O PROFISSIONAL NUTRICIONISTA E A GASTRONOMIA HOSPITALAR}

A Lei $\mathrm{n}^{0} 8.234$ de 17 de setembro de 1991 regulamenta a profissão do Nutricionista (ANEXO 1).

Dentro de um hospital o nutricionista atua junto ao médico, ao paciente, à assistência social e à administração. Possui relação direta com o bem estar do paciente, uma vez que em posse de informações sobre as limitações patológicas e particulares do indivíduo impostas em sua alimentação, determina a comida que lhe será ofertada.

\subsubsection{Atribuições do nutricionista}

Para Mezomo (2002), na área hospitalar, a integração do nutricionista com o médico que prescreve a dieta e acompanha a evolução do quadro clínico do paciente, torna-se imprescindível, bem como com a enfermeira que supervisiona de perto o comportamento do paciente. Tal integração possibilitará a recuperação do paciente em menor tempo.

Segue a atuação do nutricionista junto à equipe multiprofissional, segundo Mezomo(2002): 


\section{$>$ Junto ao médico:}

O nutricionista dietoterapeuta colabora na prescrição da dieta, dando informação sobre: os hábitos alimentares do paciente; disponibilidade econômica do mesmo; viabilidade da execução da dieta às condições já expostas; considerações da possibilidade de modificações do esquema dietético, de acordo com a evolução do quadro clínico; e substituições equivalentes dos alimentos.

\section{> Junto ao paciente:}

- informá-lo da importância da dieta para sua recuperação;

- adaptar a dieta aos alimentos preferidos do paciente e permitido na dieta;

- orientar fórmulas de preparações permitidas e que correspondam ao gosto do cliente;

- adaptar a dieta às condições econômicas, prescrevendo alimentos de fácil obtenção, preparações simples, valor comercial inferior, sem alteração do valor nutricional; e

- procurar compreender os problemas que direta ou indiretamente estejam bloqueando a recuperação do paciente.

\section{Junto ao enfermeiro:}

- receber informações quanto à aceitação da dieta;

- coordenar os horários da alimentação do paciente com a rotina de prescrições de medicamentos e outros tipos de assistências de 
enfermagem que a maioria das vezes são desagradáveis ao paciente, a fim de não coincidirem, tornando o momento das refeições o mais agradável possível;

- receber informações da conduta dos familiares nos dias de visita frente à dieta do paciente.

\section{> Junto à assistente social:}

Informa-se do momento de alta do paciente para dar orientação da dieta a ser seguida em casa, obedecendo às condições econômicas e ao hábito alimentar sem fugir do esquema dietoterapêutico prescrito, e informa-se da presença do parente mais próximo que acompanhará o paciente e dar orientação quanto à importância do seguimento da dieta, para o pronto restabelecimento da saúde do paciente. Se for uma dieta prolongada, ajudar e orientar na maneira de suavizar a dieta, evitando a monotonia do cardápio, procurando fazer a dieta parecer o mais normal possível.

\section{> Junto à administração:}

- assessorar o pessoal médico e paramédico em assuntos relativos à nutrição e dietoterapia;

- participar de programas de treinamento de alunos;

- colaborar nos programas de treinamento de alunos;

- colaborar nos programas de treinamento em serviços dos vários setores do hospital, inclusive a nutrição e dietética; 
- pesquisar a disponibilidade de alimentos dietéticos utilizáveis no hospital;

- aplicar dietas novas e acompanhar os casos, apresentando os resultados;

- acompanhar o comportamento psicossomático do paciente submetido a determinadas dietas, documentando e apresentando resultados.

Para Jorge e Marculevicius (apud Guimarães, 2007) o papel do nutricionista na Gastronomia Hospitalar é:

Implementação da cozinha de montagem com uso de produtos semiprocessados e/ou processados na linha produtiva com benefícios e aproveitamento de pessoal, redução de custos de aquisição, manutenção, meio-ambiente e mão-de-obra, investindo em recursos para a finalização de pratos.

> Implementação da variedade de produtos e serviços oferecidos à clientela (eventos; carrinhos de hotelaria, com produtos diferenciados e sistema de opções).

Implementação de testes experimentais de alimentos na cozinha experimental, para auxiliar no desenvolvimento de fornecedores e aprimoramento de processos adquiridos.

\section{No Ensino e pesquisa:}


$>$ treinamento e desenvolvimento de pessoal através de oficinas de culinária para decoração de pratos, reconhecimento e aplicação de técnicas culinárias clássicas e inovadoras associadas à dietoterapia.

realização de concurso de receitas entre a equipe de colaboradores, com inclusão de receitas na linha de produção;

desenvolvimento de novos produtos e preparações dietéticas para aprimoramento de cardápio e dietas restritas;

projeto de calibração de degustadores, direcionado a todos os nutricionistas em exercício, com determinação do perfil de sensibilidade de cada profissional para doce, salgado, azedo e amargo;

implantação de estágio curricular e voluntário para alunos de nutrição e nutricionistas em cozinha experimental e marketing de alimentos, com programa destinado à Dietoterapia, Dietética e Gastronomia Hospitalar;

participação em eventos de gastronomia e culinária, com intercâmbio institucional;

implementação de visitas externas para desenvolvimento de

benchmarking;

parcerias com instituições para bolsas de estudo em cursos especializados;

divulgação, com desenvolvimento, edição e publicação de receituários advindos de projetos direcionados à Técnica Dietética e Gastronomia. 


\subsubsection{A expectativa do cliente de saúde}

A expectativa do cliente interno pode ser avaliada através de pesquisas de opinião ou enquetes periódicas aplicadas junto aos pacientes durante a internação ou na sua avaliação após a alta.

São vários os aspectos que podem ser abordados nas pesquisas de satisfação de clientes referentes às refeições. Cada um possui um papel importante no aspecto da $\mathrm{GH}$.

qualidade das refeições (harmonia, cores, sabores, textura);

qualidade das preparações servidas em cada refeição;

variedade de cardápios;

tempo das preparações;

apresentação das bandejas;

atendimento do atendente de nutrição;

atendimento da nutricionista;

avaliação geral da prestação de serviços por parte da UND. 


\section{METODOLOGIA}

Para elaboração deste trabalho foi necessária uma revisão de literatura em livros, teses, dissertações, internet, buscando os diversos itens e subitens que compõem o tema referido. A pesquisa foi realizada em língua portuguesa.

A aplicação do questionário foi realizada no mês de agosto de 2009 e os indexadores constam no Apêndice.

O tipo de pesquisa foi exploratória, que envolve o levantamento bibliográfico e entrevistas, através da aplicação de um questionário com questões fechadas.

Gil (2007) define questionário como a técnica de investigação composta por um número mais ou menos elevado de questões apresentadas por escrito às pessoas, tendo por objetivo o conhecimento de opiniões, crenças, sentimentos, interesses, expectativas, situações vivenciadas, etc. Quando as questões são formuladas oralmente pelo pesquisador podem ser designados como questionários aplicados com entrevista ou formulário.

Quanto às questões Gil (2007) define como questões fechadas a apresentação ao respondente, um conjunto de alternativas de resposta para que seja escolhida a que melhor representar sua situação ou ponto de vista.

O questionário utilizado nesse estudo foi adaptado de acordo com as características que são relevantes e imprescindíveis para a Gastronomia Hospitalar abordadas anteriormente, de acordo com o Apêndice. 
O questionário foi aplicado pela autora em $100 \%$ da amostragem ( 9 nutricionistas), ou seja, com todas as nutricionistas de um hospital particular do Distrito Federal.

As ocupantes do cargo de Técnicas em Nutrição não fizeram parte da amostra porque desempenham funções diferentes daquelas objeto desta pesquisa.

Para elaboração do questionário buscou-se os critérios fundamentais para a Gastronomia Hospitalar.

Descrição dos Critérios utilizados:

Agrados ao cliente em datas comemorativas: cardápio especial no Natal, Ano Novo, Aniversário, dia dos pais, dia das mães, dia das crianças.

Aparência dos Funcionários: apresentação pessoal e do uniforme da copeira.

Aparência Visual: característica formada pela combinação de cores dos alimentos, tipo de corte, consistência de preparações, disposição de embalagens e utensílios na bandeja.

Atenção do Nutricionista às individualidades do cliente: anamnese para identificar aversões, intolerâncias e preferências.

Cardápio variado: existência de preparações diferentes para cada refeição servida.

Condições adequadas para alimentar-se: mobília (mesa de apoio, cadeira, mesa de refeição).

Cortesia no atendimento: gentileza e atenção apresentadas pela copeira que realiza o atendimento direto.

Higiene dos Alimentos: ausência de corpos estranhos nas bandejas e/ou preparações: cabelo, insetos, larvas, pelos e outros. 
Mensagens na bandeja no desjejum: mensagens de bom dia, de esperança, enfim de estímulo.

Necessidade da assistência do Chef de Cozinha: para elaboração das refeições oferecidas.

Sabor: paladar agradável de temperos utilizados.

Temperatura adequada dos alimentos: temperatura quente/fria de acordo com a característica de cada preparação.

Treinamento especializado dos funcionários: aplicação de treinamentos, abrangendo temas como cortesia, hospitalidade, humanização, todos visando a melhoria dos processos. Técnica, Dietética e Gastronomia.

Utensílios adequados para alimentar-se: talheres, guardanapos, embalagem.

\subsection{DESCRICÃO DO S. A. DO HOSPITAL}

O hospital situa-se em Brasília/DF, é privado, composto por 250 leitos, e está em processo de Acreditação ${ }^{4}$. Possui clínicas dedicadas às mais diversas especialidades médicas. O pronto socorro e a unidade de atendimento médicocirúrgico atendem a todas as especialidades médicas.

O Serviço de Alimentação do hospital é terceirizado e localiza-se no subsolo.

O sistema de distribuição de refeições é centralizado, ou seja, as refeições são porcionadas no próprio local onde são preparadas. O número de refeições

\footnotetext{
${ }^{4}$ O Sistema Brasileiro de Acreditação em vigor no Brasil desde 1999 surgiu a partir do Programa Brasileiro da Qualidade e Produtividade, sendo determinado que a avaliação e certificação dos serviços de saúde seriam um trabalho estratégico do Ministério da Saúde (RESK, 2001), Este sistema visa certificar a qualidade de uma unidade hospitalar de forma integral e criar uma mentalidade de melhoria contínua.
} 
diárias é de aproximadamente 1.700 para pacientes e acompanhantes. Apenas o desjejum é oferecido aos funcionários.

Organograma do SA

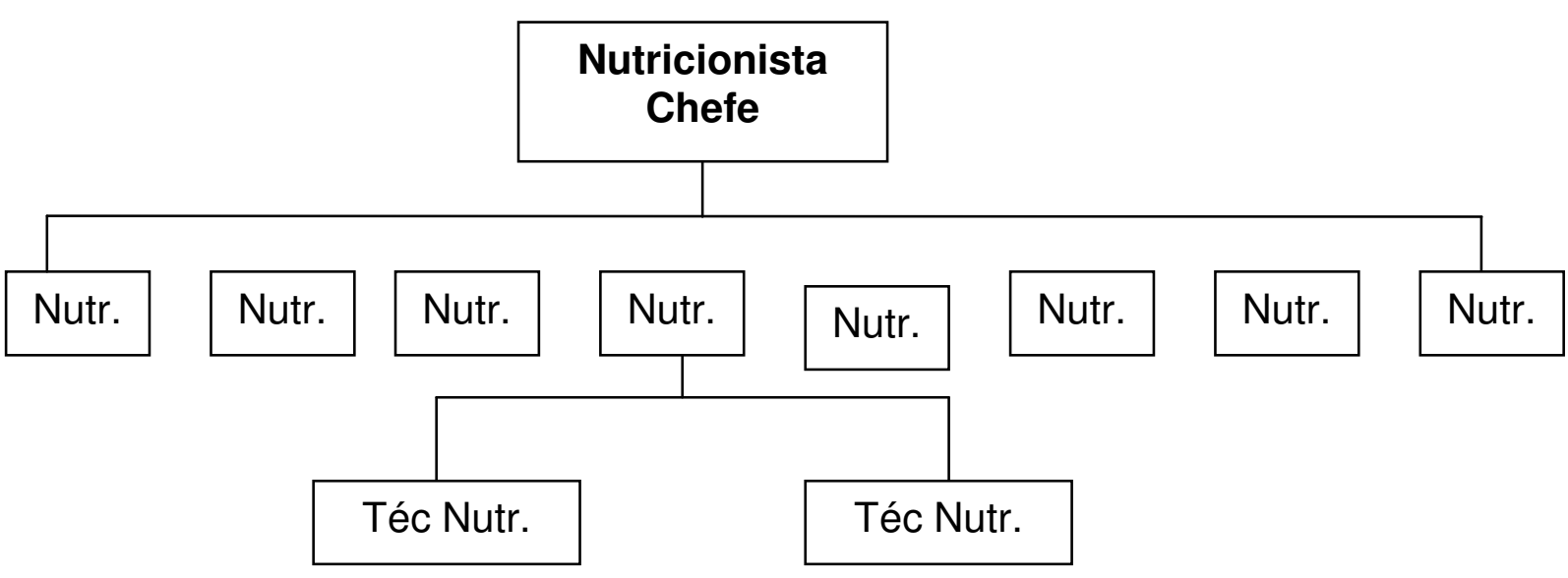




\section{RESULTADOS E DISCUSSÕES}

De acordo com o questionário aplicado com as nutricionistas foram avaliados catorze critérios que para a G. H. são considerados "muito importantes".

Os resultados de acordo com o percentual de nutricionistas que avaliaram os níveis de importância de cada critério da Gastronomia Hospitalar encontram-se na Figura 2, onde o gráfico permite uma visualização geral dos resultados obtidos.

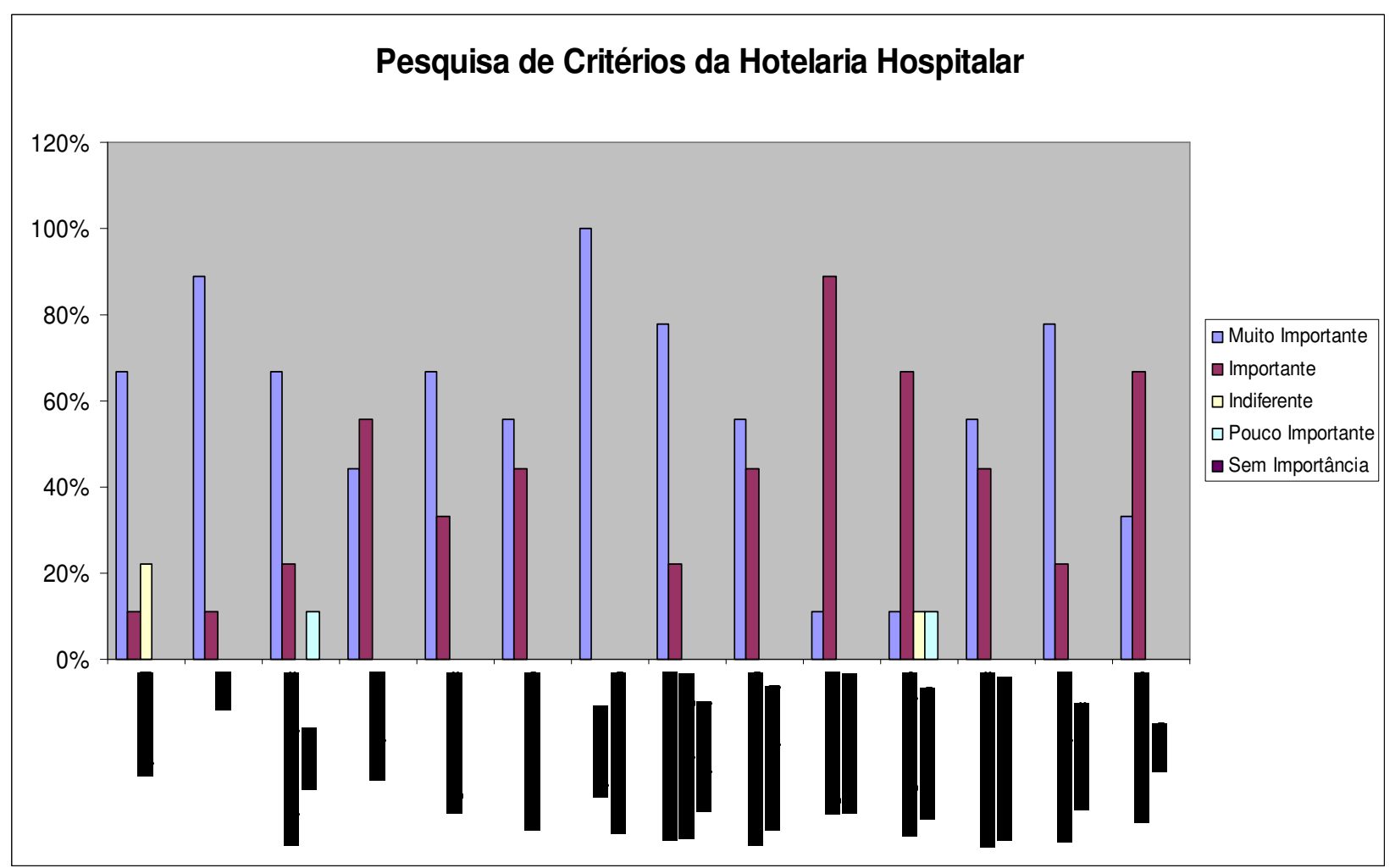

Figura 2: Resultados da percepção do profissional nutricionista quanto ao nível de Fonte: A autora importância dos principais critérios da Gastronomia Hospitalar. 


\section{$>$ Aparência visual}

Um prato bem elaborado em termos visuais, gastronômicos e nutricionais, faz toda a diferença entre aderir ou não ao planejamento nutricional, no entanto $67 \%$ dos entrevistados possuem essa visão e consideraram este critério como "muito importante".

Para Poulain o alimento é o que nutre o que traz ao homem os elementos que o dispêndio da vida Ihe faz perder. Mas, para que o alimento seja reconhecido como tal, ou seja, capaz de manter a vida, ele não deve somente possuir qualidades nutricionais, é preciso que ele seja conhecido e/ou aceito como tal pelo comedor. Através desta visão sociológica sobre o alimento percebe-se a importância de se oferecer preparações com aparência satisfatória e que seja possível ser identificada.

Para Casotti todos temos fome, comer é um grande prazer! E o desejo de se alimentar pode ser estimulado ao visualizar um prato bem elaborado, com detalhes no porcionamento, nos cortes diferenciados, na coloração ideal das preparações.

\section{Sabor}

A Gastronomia Hospitalar procura utilizar ervas, condimentos, combinações ideais de alimentos, preparações diferenciadas que realçam sabores e estimulam o apetite do cliente, nesta pesquisa $89 \%$ dos entrevistados concordam com tal afirmativa.

Leal cita que, como os pintores fazem como as cores, o verdadeiro cozinheiro tem que tornar as misturas tão homogêneas que de seus vários sabores resulte apenas um gosto sutil e instigante, uma harmonia de todos os gostos reunidos. Daí a grande contribuição da Arte Culinária. 


\section{$>$ Temperatura adequada dos Alimentos}

De acordo com Phillippi foi citado que um dos objetivos da Técnica e Dietética é o sensorial que consiste em apresentar o alimento de forma que desperte todos os sentidos, não apenas o paladar, pois cada alimento possui suas características próprias. Para tal cita-se a temperatura adequada dos alimentos: alimentos quentes devem ser servidos quentes; alimentos frios devem ser servidos frios e assim por diante. Sessenta e sete por cento dos profissionais entrevistados classificaram a temperatura das preparações como "muito importante".

\section{$>$ Cardápio variado}

Para Duarte no universo existente entre o atendimento médico e a atenção à saúde, o cardápio incorpora momentos de "alegria", daí a importância de se oferecer um cardápio variado e atraente que estimule o apetite e a satisfação em se alimentar. A oferta de preparações repetidas não encantará o cliente de saúde, que já está fora de seu convívio costumeiro e muitas vezes com limitações da própria patologia. Quarenta e quatro por cento dos entrevistados vizualizaram tais situações.

\section{Higiene dos Alimentos}

Alimentos mal higienizados implicam em risco ao cliente podendo trazer complicações indesejáveis a um indivíduo que já está com o estado de saúde comprometido. Os resultados encontrados foram que sessenta e sete por cento dos profissionais entrevistados avaliaram este critério como "muito importante".

Phillippi cita a higiene dos alimentos como um dos objetivos da Técnica e Dietética. Consiste em prevenir a ação de fatores externos que passam a prejudicar a qualidade dos alimentos, aumentando sua vida útil. 


\section{$>$ Cortesia no Atendimento}

Davies cita que "a cortesia não custa nada, mas vale tudo", e ainda afirma que se os funcionários interagem bem com os clientes, acabam influenciando-os para que retornem. Portanto, fica bem nítida a importância de um sorriso, de um "bom dia", de uma atenção especial, de um apoio, enfim todos os clientes devem sentir-se como VIP. Nessa pesquisa cinqüenta e seis por cento dos entrevistados avaliaram esse item como "muito importante".

\section{$>$ Aparência dos funcionários que servem}

Esse foi o único critério em que as respostas foram unânimes, todas as nutricionistas entrevistadas classificaram-no como "muito importante".

Para Davies a hospitalidade é definida como a recepção e a acolhida aos hóspedes/clientes, visitante-acompanhantes, estranhos, com liberalidade e boa vontade. A recepção e o atendimento devem, sempre, proporcionar um ambiente agradável. Funcionários bem vestidos com uniformes higienizados; bem passados, com bom caimento, com cores conservadas são fatores imprescindíveis.

\section{Utensílios adequados para alimentar-se}

Para Castro (apud Boeger 2005) a Gastronomia Hospitalar busca proporcionar prazer no momento da alimentação, otimizando todos os recursos disponíveis. E, ainda, cita como recurso tecnológico os utensílios utilizados para alimentar-se como pratos, talheres, copos, xícaras e outros. Ambos devem ser utilizados de acordo com a realidade de cada paciente, de maneira a mais agradável possível. Setenta e oito por cento dos entrevistados avaliaram que os utensílios adequados à realidade de cada paciente é critério "muito importante". 


\section{> Condições adequadas para alimentar-se}

Como cita Duarte (2006), a relação positiva entre o momento da alimentação e a realidade individual do mundo social extra-hospitalar promove ações sinérgicas ao tratamento medicamentoso, ou seja, o cliente, mesmo com limitações impostas pela doença ou não, se obtiver condições favoráveis, agradáveis e confortáveis no momento de sua alimentação, com certeza, aceitarão a dieta. Dos entrevistados, no entanto $56 \%$ avaliaram esse critério como muito importante.

\section{> Agrados ao cliente em datas comemorativas e mensagem na bandeja de refeição no Desjejum}

De acordo com Jorge com o surgimento e a evolução dos hospitais, apresentou-se avanços clínicos, aliados às ações de hospitalidade e hotelaria para a promoção da qualidade de vida dos clientes. Daí a importância de surpreender o cliente com ações que podem proporcionar alegria e até entusiasmo. Quem não gosta de iniciar o dia com um pensamento positivo, uma mensagem bonita: uma frase perfeita, um poema de amor, e assim por diante. Quem não gosta nos dias especiais (aniversário, natal, dia das mães, pais, crianças) de receber algo que o faça sentir "importante"? O grande segredo é que se deve encantar o cliente, sempre. Este é o objetivo principal da Hotelaria Hospitalar e apenas 11\% dos entrevistados conseguiram visualizar tal importância.

\section{> Atenção do Nutricionista às individualidades do cliente}

Guimarães cita que a H.H é composta por $5 \mathrm{Hs}$, um deles é a Humanização, que é citada como o "bem atender" que envolve todos os setores e todos os profissionais envolvidos no processo. O conceito leva em conta que o cliente é um indivíduo com necessidades, desejos e aversões que devem ser consideradas. 
Para tal é imprescindível a ação individualizada do profissional nutricionista, através de uma Anamnese Alimentar, que é descrita como uma atenção básica e primordial deste profissional e $56 \%$ dos profissionais entrevistados avaliaram este critério como "muito importante".

Esse dado chama a atenção porque vai de encontro com as ações/funções básicas do profissional nutricionista, esse deverá "enxergar" cada cliente e não uma patologia.

\section{> Treinamento Especializado dos Funcionários}

Jorge e Maculevicius (apud GUIMARÃES, 2007) cita como um dos itens para a implantação da Gastronomia Hospitalar, o treinamento de funcionários em linha de montagem; o desenvolvimento de talentos e habilidades manuais entre os colaboradores e também o treinamento e desenvolvimento de colaboradores, estimulando a formação de especialistas em Gastronomia e Dietética, podendo assim descartar a necessidade de um chef de cozinha.

O treinamento de todos os colaboradores deve ser encarado como um desafio a investimentos constantes, visando sempre a melhoria dos processos e a capacitação dos colaboradores. Este critério foi avaliado como "muito importante" por $78 \%$ dos profissionais. 


\section{Necessidades de chef de Cozinha}

Guimarães cita que um dos $\mathrm{H}$ que compõe a H.H. é o Hoteleiro, que referese à possibilidade de inserir glamour aos serviços prestados como a inserção de um chef de cozinha, que proporcionaria ao cliente pratos mais elaborados e com toque especial. Nessa pesquisa $33 \%$ dos entrevistados visualizaram esse critério como "muito importante".

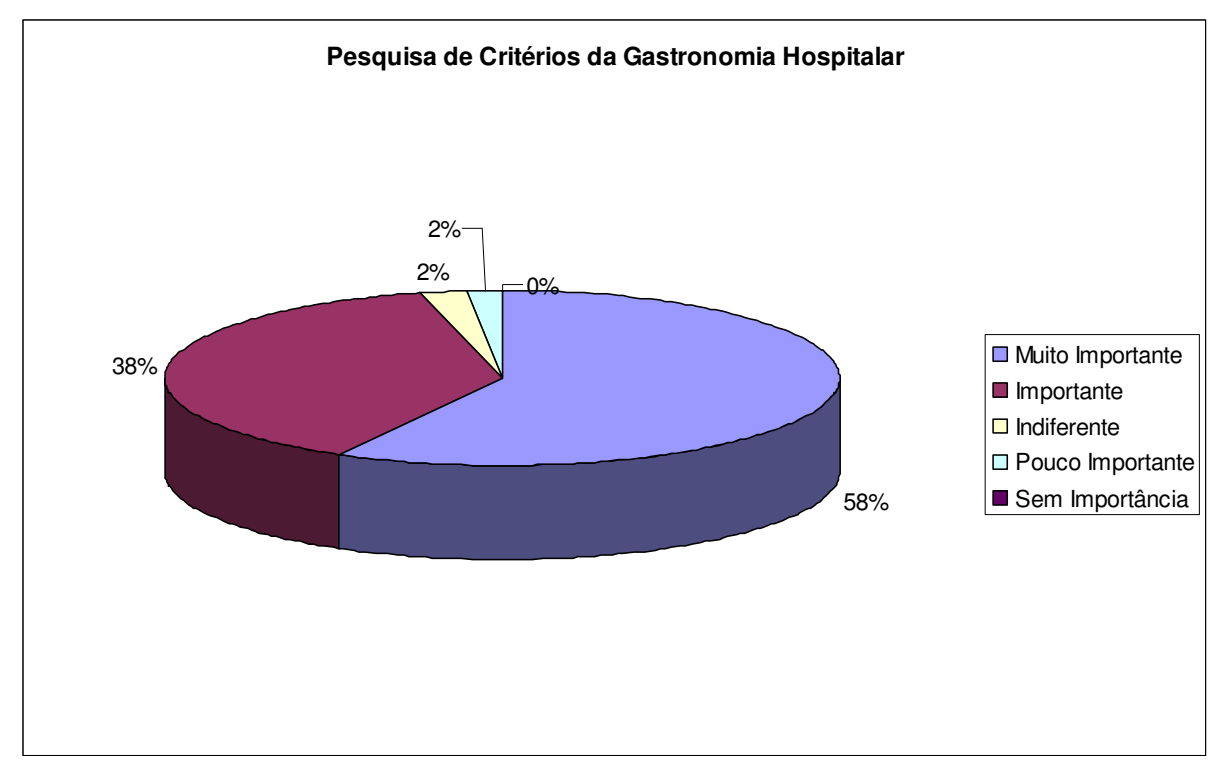

Figura 3: Gráfico consolidado dos critérios avaliados da Gastronomia Hospitalar na visão dos nutricionistas do hospital pesquisado

Fonte: A autora

Como mostra a Figura $358 \%$ dos profissionais entrevistados avaliaram alguns critérios como "muito importante", enquanto $38 \%$ avaliaram como "importante". 


\section{CONSIDERAÇÕES FINAIS}

Com o presente estudo conclui-se que somente um profissional respondeu ao questionário de acordo com o esperado, que era o do entendimento de que todos os critérios são considerados "muito importantes" pela G.H. É impossível falar em G.H sem ter uma visão globalizada sobre o assunto. Há uma associação de fatores que irão atrair os olhos do cliente. O mesmo deve sentir-se encantado e surpreendido a cada ação dos profissionais envolvidos no processo durante sua internação.

Para tal é imprescindível o trabalho multidisciplinar. Há a necessidade de integração dos diversos profissionais, ambos devem atuar em sintonia. $O$ nutricionista deverá agir sincronizadamente com o médico, com o enfermeiro, com a assistente social, com a administração e com o cliente de saúde.

Além disso, é válido ressaltar que os nutricionistas também devem executar seu trabalho de modo sincronizado, pois o hospital conta com o trabalho de vários nutricionistas.

Para que seja possível a oferta de um atendimento diferenciado, todos os profissionais que estão envolvidos direta ou indiretamente nos processos, devem ter como objetivo comum o crescimento da empresa, deixando as diversidades de lado.

Parte-se do princípio que os bons profissionais seguem a seguinte norma : "o possível faremos imediatamente e o impossível toma só um pouquinho mais de tempo". 
Proporcionar momentos de alegria e prazer para quem está com a saúde comprometida e fora do seu convívio familiar é algo muito satisfatório e gratificante, a alimentação é um dos caminhos que pode levar a este fato,

O cliente deve sentir-se como a medida das coisas, como a razão de ser das instituições que o atendem e para isso suas individualidades devem ser consideradas e o seu tratamento deve ser conduzido baseando-se nas anamneses.

O cliente deve ser otimista e esperançoso tendo o seu corpo como algo sempre possível de melhorar, aperfeiçoar, adaptar às limitações impostas pela doença, daí a grande importância de oferecer ambientes e situações aconchegantes, acolhedoras e surpreendentes.

A Hotelaria Hospitalar e a Gastronomia Hospitalar vêm com várias propostas para que o encantamento do cliente seja freqüente.

Para que os profissionais possam oferecer atendimentos diferenciados devem, ser também diferenciados. Daí a importância de investir em cursos de atualização; aprimoramento; especializações, visto que a área da saúde é muito complexa, cresce e apresenta novidades a cada momento.

O conhecimento deve ser uma busca incessante de todos os profissionais da saúde, que optaram por trabalhar com a cura! 


\section{REFERÊNCIAS BIBLIOGRÁFICAS}

BOEGER, Marcelo Assad. Gestão e Hotelaria Hospitalar. 2 ed. São Paulo: Atlas, 2005.

CASOTTI, Letícia. À mesa com a família. 1 ed. Rio de Janeiro: Mauad editora, 2002.

DAVIES, Carlos Alberto. Alimentos e Bebidas. 2 ed. Caixas do Sul: EDUCS, 2001.

DUARTE, Rafaela. Gastronomia Hospitalar, 2006. Disponível em www.hospitaldocoraçao.com.br. Acesso em 17 mar. 2009.

GIL, Antônio Carlos. Métodos e Técnicas de Pesquisa Social. 5 ed. São Paulo: Atlas, 2007.

GUIMARAES, Nísia do Val Rodrigues Roxo. Hotelaria Hospitalar: uma visão interdisciplinar. 2 ed. São Paulo: Atheneu, 2007.

JORGE, Andrea Luíza. História e Evolução da Gastronomia Hospitalar, 2006. Disponível em www.asbran.org.br. Acesso em 17 mar. 2009.

LEAL, Maria Leonor de Macedo Soares. A história da Gastronomia. 2 ed. Rio de Janeiro: SENAC Nacional, 1998.

MAGNONI, Daniel. Gastronomia Hospitalar favorece o bem estar dos pacientes internados, 2005. Disponível em www.nutricaoclínica.com.br. Acesso em 17 mar. 2009.

MEZOMO, Iracema de Barros. Os Serviços de Alimentação. 5 ed. São Paulo: Manole,2002.

MONTANARI, Massimo; FLANDRIN, Jean. História da Alimentação. 2 ed. São Paulo: Estação da Liberdade, 1998.

PHILIPPI, Sonia Tucunduva. Nutrição e Técnica Dietética. 1 ed. São Paulo: Manole, 2003.

POULAIN, Jean Pierre. Sociologias da Alimentação. 1 ed. Florianópolis: UFSC, 2004.

RESK, S.S, Brasil: busca da isonomia do sistema de saúde. Revista Banas Qualidade. São Paulo: ano 10, n. 105, p. 37, feveiro, 2001.

SANTOS, Lígia Amparo da Silva. O corpo, o comer e a comida. 1 ed. Salvador: EDUFBA, 2008. 


\section{BIBLIOGRAFIA}

LIMA, Priscila Acioli. Manual de Boas Práticas de uma Unidade de Alimentação. Brasília: CET: UNB, 2006.

LOUZADA, Juliana Damasceno. Gastronomia Brasília: CET, UNB, 2006.

MARIMOTO, Ivone Mayumi Ikeda. Melhoria da qualidade na Unidade de Alimentação e Nutrição Hospitalar: um modelo prático: Florianópolis: Universidade Federal de Santa Catarina, 2002.

RIEKES, Bethania Hering. Qualidade em Unidades de Alimentação e Nutrição: uma proposta metodológica considerando os aspectos nutricionais e sensoriais. Florianópolis: Universidade Federal de Santa Catarina, 2004.

SCHILLING, Magali. Qualidade em Nutrição: métodos de melhorias contínuas ao alcance de indivíduos e coletividades. 2 ed. São Paulo: Varela, 1995.

TEIXEIRA, Suzana, et. al. Administração Aplicada às Unidades de Alimentação e Nutrição. 11 ed. São Paulo: Atheneu, 2007. 


\section{LEI № 8.234, DE 17 DE SETEMBRO DE 1.991 (DOU 18/09/1991) REGULAMENTA A PROFISSÃO DE NUTRICIONISTA E DETERMINA OUTRAS PROVIDÊNCIAS}

A Lei no 8.234 de 17 de setembro de 1991 regulamenta a profissão do Nutricionista.

Art. 1‥ A designação e o exercício da profissão de Nutricionista, profissional de saúde, em qualquer de suas áreas, são privativos dos portadores de diploma expedido por escolas de graduação em nutrição, oficiais ou reconhecidas, devidamente registrado no órgão competente do Ministério da Educação e regularmente inscrito no Conselho Regional de Nutricionistas da respectiva área de atuação profissional.

Art. 2․ A carteira de Identidade Profissional, emitida pelo Conselho Regional de Nutricionistas da respectiva jurisdição, é, para quaisquer efeitos, o instrumento hábil de identificação civil e de comprovação de habilitação profissional do nutricionista, nos termos da Lei no 6.206, de 7 de maio de 1975, e da Lei no 6.583, de 20 de outubro de 1978.

Art. 3‥ São Atividades privativas dos nutricionistas:

I - direção, coordenação e supervisão de cursos de graduação em nutrição;

II - planejamento, organização, direção, supervisão e avaliação de serviços de alimentação e nutrição;

III - planejamento, coordenação, supervisão e avaliação de estudos dietéticos;

IV - ensino das matérias profissionais dos cursos de graduação em nutrição;

V - ensino das disciplinas de nutrição e alimentação nos cursos de graduação da área de saúde e outras afins;

VI - auditoria, consultoria e assessoria em nutrição e dietética; 
VII - assistência e educação nutricional a coletividades ou indivíduos, sadios ou enfermos, em instituições públicas e privadas e em consultório de nutrição e dietética;

VIII - assistência dietoterápica hospitalar, ambulatorial e a nível de consultórios de nutrição e dietética, prescrevendo, planejando, analisando, supervisionando e avaliando dietas para enfermos. 


\section{APÊNDICE}

Ficha de coleta de dados para suporte prático

Nutricionista:

Entrevistadora:

Data:

Qual sua opinião sobre o grau de cada item ao definir Gastronomia Hospitalar?

\begin{tabular}{|l|l|l|l|l|l|}
\hline \multicolumn{1}{|c|}{ Critérios } & $\begin{array}{c}\text { Muito } \\
\text { Importante }\end{array}$ & Importante & Indiferente & $\begin{array}{c}\text { Pouco } \\
\text { importante }\end{array}$ & $\begin{array}{c}\text { Sem } \\
\text { importância }\end{array}$ \\
\hline $\begin{array}{l}\text { Aparência } \\
\text { Visual }\end{array}$ & & & & & \\
\hline Sabor & & & & & \\
\hline $\begin{array}{l}\text { Temperatura } \\
\text { adequada dos } \\
\text { alimentos }\end{array}$ & & & & & \\
\hline $\begin{array}{l}\text { Cardápio } \\
\text { Variado }\end{array}$ & & & & & \\
\hline $\begin{array}{l}\text { Higiene dos } \\
\text { Alimentos }\end{array}$ & & & & & \\
\hline $\begin{array}{l}\text { Cortesia no } \\
\text { atendimento }\end{array}$ & & & & & \\
\hline $\begin{array}{l}\text { Aparência dos } \\
\text { funcionários } \\
\text { que servem }\end{array}$ & & & & & \\
\hline $\begin{array}{l}\text { Utensílios } \\
\text { adequados } \\
\text { para alimentar- } \\
\text { se } \\
\text { (embalagens, } \\
\text { bandeja, } \\
\text { talheres) }\end{array}$ & & & & & \\
\hline $\begin{array}{l}\text { Condições } \\
\text { adequadas } \\
\text { para alimentar- } \\
\text { se (mobília) }\end{array}$ & & & & & \\
\hline $\begin{array}{l}\text { Agrados ao } \\
\text { cliente } \\
\text { datas } \\
\text { comemorativas }\end{array}$ & & & & & \\
\hline $\begin{array}{l}\text { Mensagem na } \\
\text { bandeja do } \\
\text { desjejum }\end{array}$ & & & & & \\
\hline $\begin{array}{l}\text { Atenção do } \\
\text { Nutricionista as } \\
\text { individualidades } \\
\text { do cliente }\end{array}$ & & & & & \\
\hline $\begin{array}{l}\text { Treinamento } \\
\text { especializado } \\
\text { dos } \\
\text { funcionários }\end{array}$ & & & & & \\
\hline $\begin{array}{l}\text { Necessidades } \\
\text { da existência } \\
\text { de chef de } \\
\text { cozinha }\end{array}$ & & & & & \\
\hline
\end{tabular}

